\title{
Green Supplier Selection for Process Industries Using Weighted Grey Incidence Decision Model
}

\author{
Jing Quan $\mathbb{D}^{1},{ }^{1}$ Bo Zeng $\mathbb{D}^{2},{ }^{2}$ and Dai Liu ${ }^{2}$ \\ ${ }^{1}$ School of Science, Chongqing University of Technology, Chongqing, China \\ ${ }^{2}$ Rongzhi College of Chongqing Technology and Business University, Chongqing, China \\ Correspondence should be addressed to Bo Zeng; bozeng@ctbu.edu.cn
}

Received 16 February 2018; Revised 7 May 2018; Accepted 14 September 2018; Published 8 October 2018

Guest Editor: Sotiris Makris

Copyright (c) 2018 Jing Quan et al. This is an open access article distributed under the Creative Commons Attribution License, which permits unrestricted use, distribution, and reproduction in any medium, provided the original work is properly cited.

\begin{abstract}
Proper supplier selection to meet production demand is a major aspect of all manufacturing and process industries. Green supplier selection has been one of the most critical factors for environmental protection on account of increasing consumption levels and for sustainable development as well. This paper aims at developing an applicable methodology for green supplier selection for the process industry. In this study, both economic and environmental criteria are considered and a comprehensive weighted grey incidence decision approach for green supplier evaluation and selection in a process industry is proposed. First, an overall green supplier selection index system for process industries is considered; then a weighted grey incidence decision-making model with improved grey incidence coefficients and weighted degree of grey incidence is provided. Improved grey incidence coefficients are defined using transformation sequences of the initial data. To eliminate the ill effects from the use of equal weights, the maximum entropy method is used to determine the weights of the improved grey incidence coefficients. An application example is proposed with the data collected for the chemical processing industry, which provides acceptable results in determining the better supplier. In the end appendix, some theory regarding the weights for grey incidence coefficients is proposed. The empirical results indicate that the model is of great practical value for green supplier selection in the process industry.
\end{abstract}

\section{Introduction}

The supply chain is a series of activities to procure materials, process them into intermediate goods and final products, and deliver them to customers, which encompasses all links from suppliers to customers. Supply chain management quests to conduct the physical and information flow exchanged amongst all actors in a supply chain [1] best. Effective supply chains can establish a long-term effective collaboration amongst different businesses. Supplier selection is the process in which companies identify, evaluate, and contract with suppliers [2]. In today's Internet world, competitive business circumstances have caused many companies to elevate the importance of supply chain management and supplier selection, and businesses pay particular attention to identification and selection amongst alternative supply sources. Once a supplier becomes a partner, the relationship between the buyer and supplier will have a critical effect on the competitiveness of the entire supply chain. As most companies expend a considerable amount of their revenues on purchasing, the supplier selection process has become one of the most important issues for establishing an effective supply chain management system [3]. As organizations become more and more dependent on suppliers, the direct and indirect consequences of poor decision-making in selecting suppliers will become more critical [4].

Supplier selection is a complex decision-making process. Before the companies made decisions based almost exclusively on price and quantity, most of the modern researchers consider that the combination of factors should fit not only the economic and technical requirements but also a company's strategy [5]. Ho et al. suggested that global criteria should be applied to effectively evaluate supplier selection [6]. Traditional supplier selection models focus on suppliers' economic and technical efficiency but ignore the ecological efficiency of the supplier. Today, organizations should consider the environmental awareness of suppliers and demand that their suppliers reduce their environmental impacts [7]. 
Apart from the common criteria such as cost and quality, the research [8] discussed the green issues which can play an important role in sourcing and proposed critical environmental variables which can be used in supplier selection.

With the advent of industrialization, green supply chain management can be regarded as a strategy in which all supply chain members attain more value. Today's competitive markets have forced companies to focus on environmental issues aligned with other critical factors (cost, quality, service level, etc.) to increase the supply chain value. Hence, green supplier selection to reduce the purchase risk is one of the most important decision-making issues. There are many studies dedicated to supplier selection based on conventional criteria [4], while more and more literature [9-14] regarded green supplier evaluation or works which considered environmental criteria.

There are many different ways based on data envelopment analysis, cluster analysis, categorical methods, casebased-reasoning systems, decision models for the final choice phase, linear weighting models, statistical models, mathematical programming models, and artificial intelligence models $[15,16]$ for supplier selection decision.

Grey theory was proposed by Deng [17-19], and it is a mathematical theory that was derived from the concept of the grey set theory. It is one of the effective methods used to solve uncertainty problems under sparse data and incomplete information. The major advantage of the grey theory is that it is suitable to handle both incomplete information and unclear problems. It is used as an analysis tool when there is not enough data. Grey theory has been widely applied to prediction analysis [20-22] and decision-making [23]. As a significant portion of grey theory, grey incidence analysis has been successfully applied to social, economic, industrial, and agricultural fields and has solved a large number of scientific and production problems [24].

Grey incidence analysis is largely applied in the areas of project selection, prediction analysis, and performance evaluation. Tsai et al. [25] have developed a supplier selection model for the garment industry using grey incidence analysis. Yang and Chen [26] proposed an integrated model by combining the analytical hierarchy process and grey incidence analysis to evaluate and select the supplier for a notebook computer manufacturer. Li et al. [27] used the rough set theory for supplier selection. They converted the linguistic variable assigned to the alternatives into a grey number; based on grey theory, the suppliers were ranked. Wu et al. [28] discussed the use of a grey multiobjective decisionmaking approach to select a better site for a hypermarket in a Taiwanese city. They compared their findings with the multiplicative competitive interaction model and found that the grey approach yielded the better solution. Cao et al. [29] developed an integrated grey decision model for the selection of the material of a product.

Supplier selection decisions have become one of the most significant responsibilities of managers as well as the most critical and complex issues they must deal with. Furthermore, green supply chain performance measures must be considered in the supplier selection process, and green supplier selection decision-making for the chemical process industry has seldom been studied. Most methods for supplier selection are analytic hierarchy processes $[1,3,4]$, which depend on subjective data provided by experts. In [25-29], grey incidence analysis with equal weighting has been used for supplier selection, as it does not require large or regular data samples and hence has an important practical significance. However, their methods require subjective data from experts and equally weighted factors and initial data to form behavioural sequences are needed to calculate the degree of grey incidence in Deng's grey incidence analysis. However, certain grey information cannot be directly obtained, and the correlation coefficients of each sequence at different times are of different importance to the system. Therefore, in this context, a suitable green supplier selection decision-making method for the chemical process industry based on an improved grey incidence model is proposed, in which both economic and environmental criteria for chemical processing industry supplier selection are considered, and improved grey incidence coefficients are defined using transformation sequences of the initial data. The updated weighted grey coefficient optimization model is then established to determine the weights to obtain improved correlation coefficients.

The remainder of this paper is organized as follows: in Section 2, we construct a green supplier selection index system for process industries. The improved weighted grey incidence decision model is presented in Section 3. In Section 4, a practical application of the green supplier evaluation and selection decision method for process industries is demonstrated. The discussion of the advantage of the weighted grey incidence decision model compared to other related methodologies is given in Section 5. In Section 6, some relevant conclusions on the green supplier evaluation and selection decision model are discussed. Finally, the appendix contains the proofs of the mathematical statements in the paper.

\section{Green Supplier Selection Index System for Process Industries}

In this section, we discuss what criteria should be taken into account in green supplier selection processes. In reviewing the literature, several conventional criteria have been identified by scholars. Ho et al. [6] concluded in a literature review of supplier selection models that the most popular economic criteria amongst researchers are cost, quality, delivery, management, technology, and flexibility. With a focus on environmental awareness, more and more authors are addressing supplier selection in the light of environmental aspects, such as Handfield et al. [10], Lee et al. [13], and Sarkis [30]. Yang et al. [31] first used the Delphi method to determine the critical activities and developed the system of environmental management and green product. Environmental criteria may include pollution production, pollution control, resource consumption, green product, environmental management, ecodesign, green image, green competencies, staff environmental training, and management commitment.

However, a firm should consider both environmental and conventional factors in order to select the most appropriate 
TABLE 1: Green supplier selection criteria.

\begin{tabular}{|c|c|c|}
\hline Number & Criteria & Related attributes \\
\hline 1 & Cost & Product price, logistics cost, manufacturing cost, waste disposal cost, cost reduction performance \\
\hline 2 & Quality & $\begin{array}{l}\text { Product stability, product qualification ratio, low toxicity, process improvement, quality assurance, } \\
\text { quality management, quality-related certificates, rejection by customers }\end{array}$ \\
\hline 3 & Delivery & $\begin{array}{c}\text { Order processing speed, supplier lead time, delivery time, delivery reliability, delivery delays, } \\
\text { waiting time, credible delivery }\end{array}$ \\
\hline 4 & Service & $\begin{array}{c}\text { Warranty, responsiveness, stock management, capability of design, capability of technology } \\
\text { support, flexibility }\end{array}$ \\
\hline 5 & Technique capability & $\begin{array}{l}\text { Manufacturing capacity, technological development, technological compatibility, technology } \\
\text { level supplier's speed in development, capability of preventing pollution }\end{array}$ \\
\hline 6 & Green product & Green packaging, recycling, remanufacturing, reuse \\
\hline 7 & Pollution control & $\begin{array}{l}\text { Solid wastes, waste water, energy consumption, average volume of air pollutants, harmful } \\
\text { materials released, use of harmful materials }\end{array}$ \\
\hline 8 & Environmental management & $\begin{array}{l}\text { Environment-related certificates such as ISO 14000, green process planning, internal control } \\
\text { process, and low carbon measures }\end{array}$ \\
\hline
\end{tabular}

supplier for partnership. Existing works have generally considered environmental aspects only, for example, Lee et al. [13] and Kuo et al. [14]. This study intends to present a comprehensive green supplier selection framework by considering both economic and environmental criteria and is conducted to extract both classic and green performance measures. We concentrated on business issues such as cost, quality, delivery, service, and technology to create opportunities for long-term collaboration with suppliers. Green criteria such as pollution control, green product, and environmental management systems are also integrated with the selection criteria for better consideration of the supplier selection process [8]. Having compared different studies in the literature, in this study, we select eight criteria: cost, quality, delivery, service, technique capability, pollution control, green product, and environmental management, as the main factors of the green supplier selection process according to previous research. Table 1 presents the summary of the most important criteria in the research literature.

(1) Cost: cost can be viewed as one of the most important factors for supplier selection decision-making. Proper suppliers can reduce the cost and provide buyers with better competencies in the market. Cost consists of product price, logistics cost, manufacturing cost, inventory charge, energy charge, maintenance expense, inspection expense, and security expense, as well as waste disposal costs as an environmental factor and cost reduction performance

(2) Quality: to improve production quality, the management must consider quality control and process improvement. Quality assurance can meet customer demands for optimal utilization of resources and coincides with a firm's objectives. Total quality management and quality-related certificates such as ISO 9000, EN 29000, and BS 5750 are taken into account. Low toxicity and rejection by customers can also reflect the quality
(3) Delivery: to satisfy the customer market, firms must cooperate with the right supplier, who provides their requirements at the proper time, at the right place, under the right conditions, and with the right service. Order fulfilment capability consists of order fulfilment planning, product execution, distribution management, and cross application integration. Order processing speed, supplier lead time, delivery time, delivery reliability, delivery delays, waiting time, and credible delivery are the main components of lead time

(4) Service: in the 21 st century's competitive business environment, companies not only have to try to satisfy the demand of customers for high-quality products at competitive prices but also must operate at a high service level with good stock management and design capability to achieve customer satisfaction. Firms can achieve this goal by fast deliveries, low costs, minimum wastage, quick response, high productivity, low stocks, no damage, few mistakes, high staff morale, and so on

(5) Technique capability: technique capability is the life of a company. Advanced manufacturing technology will assist the enterprise to become a leader in its field. Therefore, manufacturing capabilities and new technology development capabilities of the supplier are necessary to meet the current and future demands of the firm. Additionally, a new product design by the supplier, technological compatibility, capacity, and speed in development should be considered

(6) Green product: there has been a greater focus on a green competency amongst vendors and suppliers, which has strategic value and favours company image in recent years. Green packaging is a type of packaging which aims at protecting the environment by using environment-friendly materials which can be recycled or reused 
(7) Pollution control: pollution control is an important reference indicator which influences the choice of a supplier. Suppliers' attitude toward pollution is becoming a determining factor for partnerships. Pollution not only destroys the environment with solid wastes and wastewater but also leads to superfluous energy consumption. Therefore, contamination control can lead to proper usage of energy for suppliers. To reduce pollution in general, the use of harmful materials must be confined

(8) Environmental management: the goals of environmental management systems are to compel firms to reduce the negative impacts of production to the environment and force buyers to be more aware of the environment, influencing firms in their decisionmaking. Environment-related certificates such as ISO 14000 , green process planning, internal control process, and low carbon measures are the main considered indicators of environmental management

In summary, green supplier selection has become an interesting topic to researchers owing to increasing awareness of environmental protection and its long-term effect on business and marketing performance.

\section{Proposed Weighted Grey Incidence Decision Model}

Grey incidence analysis uses information from the grey system to dynamically compare each factor quantitatively. The relational analysis suggests how to make predictions and decisions and generates reports that offer suggestions for supplier selection. Grey incidence analysis is a method to analyse the relational grades for discrete sequences. This is unlike the traditional statistics analysis handling the relationships between variables. Statistical analysis works with sufficient data, and the data distribution must be typical. However, grey incidence analysis requires fewer data and can analyse many factors that can overcome the disadvantages of the statistics method.

The following preliminaries can be found in $[23,24]$. In system analysis, one first chooses the quantity which reflects the characteristics of a system best. Afterwards, the factors that influence the behaviour of the system are determined. Then a quantitative analysis is considered; subsequently, one needs to process the chosen characteristic quantities, and the available data are converted to relevant nondimensional values of roughly equal magnitude by using sequence operators. The main procedure of grey incidence analysis first translates the performance of all alternatives into a comparability sequence. This step is called grey relational generating.

Definition 1 [24]. Assume that $X_{i}$ is a factor of a system, and its observation value at the ordinal position $k$ is $x_{i}(k)$, where $k=1,2, \cdots, n$. Then, $X_{i}=\left(x_{i}(1), x_{i}(2), \cdots, x_{i}(n)\right)$ is called a behavioural sequence of factor $X_{i}$. If $k$ stands for the time order, then $x_{i}(k)$ represents the observational value of factor
$X_{i}$ at the time moment $k$, and $X_{i}$ is called a behavioural time sequence. If $k$ is an ordinate of some criteria and $x_{i}(k)$ is the observation of the factor $x_{i}$ at the criteria $k$, then $X_{i}$ is called a behavioural criterion sequence. If $k$ is the ordinal number of the object observed and $x_{i}(k)$ stands for the observation of the factor $X_{i}$ of the $k$ th objective, then $X_{i}$ is called a behavioural horizontal sequence.

Regardless of the sequence (time, criterion, or horizontal), the required incidence analysis can always be conducted.

Definition 2 [23]. Let $X_{i}=\left(x_{i}(1), x_{i}(2), \cdots, x_{i}(n)\right)$ be a behavioural sequence of factor $X_{i}$, where $i=1,2, \cdots, m$. $D$ is a sequence operator such that $X_{i} D=\left(x_{i}(1) D, x_{i}(2) D, \cdots\right.$, $\left.x_{i}(n) D\right)$, where $x_{i}(k) D=\left(x_{i}(k) / x_{i}(1)\right), x_{i}(1) \neq 0$, and $k=1$, $2, \cdots, n$. Then, $D$ is referred to as an initializing operator, and $X_{i} D$ is the initial image of $X_{i}$.

According to these sequences, a reference sequence (ideal target sequence) can be defined.

Definition 3 [24]. Assume that $X_{0}=\left(x_{0}(1), x_{0}(2), \cdots, x_{0}(n)\right)$ is a sequence of data representing a system characteristic, and for all $i, X_{i}$ is a sequence of relevant factors. For a given real number $\xi \in(0,1)$, let

$$
\begin{aligned}
\gamma_{0 i}(k) & =\gamma\left(x_{0}(k), x_{i}(k)\right) \\
& =\frac{\min _{j} \min _{r}\left|x_{0}(r)-x_{j}(r)\right|+\xi \max _{j} \max _{r}\left|x_{0}(r)-x_{j}(r)\right|}{\left|x_{0}(k)-x_{i}(k)\right|+\xi \max _{j} \max _{r}\left|x_{0}(r)-x_{j}(r)\right|}, \\
\gamma\left(X_{0}, X_{i}\right) & =\frac{1}{n} \sum_{k=1}^{n} \gamma\left(x_{0}(k), x_{i}(k)\right) .
\end{aligned}
$$

Then, $\gamma\left(X_{0}, X_{i}\right)$ is called the degree of grey incidence of $X_{i}$ with respect to $X_{0}, \gamma\left(x_{0}(k), x_{i}(k)\right)$ is the incidence coefficient of $X_{i}$ with respect to $X_{0}$ at point $k$, and $\xi$ is the distinguishing coefficient.

The grey incidence coefficients between all comparability sequences and the reference sequence are then calculated. Based on these grey incidence coefficients, the grey incidence grade between the reference sequence and every comparability sequence is calculated. If a comparability sequence translated from an alternative has the highest grey incidence grade between the reference sequence and itself, that alternative will be the best choice.

In this study, the procedure used in the improved weighted grey incidence model for green supplier selection consists of eight steps: (I) determination of selection index data, (II) generation of referential series, (III) normalization of the data set, (IV) construction of the differential information data, (V) set up of the grey incidence coefficient, (VI) determination of the weight of grey incidence coefficient, (VII) calculation of the degree of grey incidence, and (VIII) determination of the grades of suppliers. The supplier with the highest degree of grey incidence is considered the optimal supplier. 
3.1. Step I: Determination of Selection Index Data. Green supplier selection is based on the critical factors comprising the selection index: cost, supply quality, lead time to delivery, warranty and capacity of the supplier, green product, pollution control, and environmental management. The decision criteria may be represented by $C_{1}, C_{2}, \cdots, C_{n}$. Experts were also asked to consider industry specifications within the decision-making process. The structure of the decision problem consists of $m$ alternatives: supplier 1 , supplier $2, \ldots$, supplier $m$. Each alternative can be evaluated in terms of the decision criteria in both qualitative and quantitative terms.

$$
\left\{\begin{array}{l}
X_{1}=\left(x_{1}(1), x_{1}(2), \cdots, x_{1}(n)\right), \\
X_{2}=\left(x_{2}(1), x_{2}(2), \cdots, x_{2}(n)\right), \\
\cdots, \\
X_{m}=\left(x_{m}(1), x_{m}(2), \cdots, x_{m}(n)\right) .
\end{array}\right.
$$

3.2. Step II: Generation of Referential Series $X_{0}$. The referential series $X_{0}$ is the optimal value for each criterion, where $x_{0}(k)$ is some observation value, and it may be the largest or the smallest of $\left\{x_{1}(k), x_{2}(k), \cdots, x_{m}(k)\right\}$. When the larger value of some criteria is better, we let $x_{0}(k)$ be the largest of $\left\{x_{1}(k), x_{2}(k), \cdots, x_{m}(k)\right\}$. When the smaller data of some criteria is better, we let $x_{0}(k)$ be the smallest of $\left\{x_{1}(k), x_{2}(k), \cdots, x_{m}(k)\right\} . X_{0}$ is used to compare with the value of all alternative suppliers.

3.3. Step III: Normalization of Data Set. The main idea of grey incidence is to determine whether the relationship between sequence curves is close according to the similarity of their shape. The aim is to display the correlation between factors quantitatively. Incidence analysis is the basis for grey system analysis and forecasting. To obtain grey information of the factors quantitatively, we perform the following grey transformation. The series data in this case can be normalized using one of two approaches; for a criteria whose larger value is better (quality, warranty and capacity), it can be normalized using formula (3a), while for a criteria whose smaller value is better (cost and delivery), it can be normalized using formula (3b).

$$
\begin{array}{ll}
y_{i}(k)=\frac{x_{0}(k)}{x_{i}(k)}, & \text { if } x_{0}(k) \text { is the smallest one of } \\
& x_{i}(k), i=1,2, \cdots, m, k=1,2, \cdots, n, \\
y_{i}(k)=\frac{x_{i}(k)}{x_{0}(k)}, & \text { if } x_{0}(k) \text { is the biggest one of } \\
& x_{i}(k), i=1,2, \cdots, m, k=1,2, \cdots, n .
\end{array}
$$

Then, we can obtain the normalization sequences:

$$
\left\{\begin{array}{l}
Y_{1}=\left(y_{1}(1), y_{1}(2), \cdots, y_{1}(n)\right), \\
Y_{2}=\left(y_{2}(1), y_{2}(2), \cdots, y_{2}(n)\right), \\
\cdots, \\
Y_{m}=\left(y_{m}(1), y_{m}(2), \cdots, y_{m}(n)\right) .
\end{array}\right.
$$

3.4. Step IV: Construction of the Differential Information Data. Now, we construct the differential information of grey incidence as follows:

$$
\Delta_{0 i}(k)=\frac{1}{1+\lambda\left|1-y_{i}(k)\right|}, \quad i=1,2, \cdots, m, k=1,2, \cdots, n,
$$

where $\lambda>0$ is some fixed number and $y_{i}(k)$ is defined by (3a) and (3b). Thus, we obtain the differential information sequences:

$$
\left\{\begin{array}{l}
\Delta_{01}=\left(\frac{1}{1+\lambda\left|1-y_{1}(1)\right|}, \frac{1}{1+\lambda\left|1-y_{1}(2)\right|}, \cdots, \frac{1}{1+\lambda\left|1-y_{1}(n)\right|}\right), \\
\Delta_{02}=\left(\frac{1}{1+\lambda\left|1-y_{2}(1)\right|}, \frac{1}{1+\lambda\left|1+y_{2}(2)\right|}, \cdots, \frac{1}{1+\lambda\left|1-y_{2}(n)\right|}\right), \\
\Delta_{0 m}=\left(\frac{1}{1+\lambda\left|1-y_{m}(1)\right|}, \frac{1}{1+\lambda\left|1-y_{m}(2)\right|}, \cdots, \frac{1}{1+\lambda\left|1-y_{m}(n)\right|}\right) .
\end{array}\right.
$$

3.5. Step V: Set-Up of Grey Incidence Coefficients. Assume that $X_{0}=\left(x_{0}(1), x_{0}(2), \cdots, x_{0}(n)\right)$ is a sequence of data representing a system's characteristics, and for all $i, X_{i}$ is a sequence of relevant factors. For a given real number $\xi \in(0,1)$, let

$$
\gamma_{0 i}(k)=\frac{\min _{j} \min _{r} \Delta_{0 j}(r)+\xi \Delta_{0 i}(k)}{\min _{j} \min _{r} \Delta_{0 j}(r)+\xi \max _{j} \max _{r} \Delta_{0 j}(r)},
$$

where $\Delta_{0 i}(k)$ is defined by (5); then $\gamma_{0 i}(k)$ is called the incidence coefficient of $X_{i}$ with respect to $X_{0}$ at point $k$, where $\xi$ is called the distinguishing coefficient. Therefore, we obtain the grey incidence coefficient sequences:

$$
\left\{\begin{array}{l}
\gamma_{01}=\left(\gamma_{01}(1), \gamma_{01}(2), \cdots, \gamma_{01}(n)\right), \\
\gamma_{02}=\left(\gamma_{02}(1), \gamma_{02}(2), \cdots, \gamma_{02}(n)\right), \\
\cdots \\
\gamma_{0 m}=\left(\gamma_{0 m}(1), \gamma_{0 m}(2), \cdots, \gamma_{0 m}(n)\right) .
\end{array}\right.
$$

3.6. Step VI: Determination of the Weight of Grey Incidence Coefficients. The basis of the grey incidence model is proximity and similar factors to determine the degree of incidence coefficient according to the curve. Past researches take equal weighted incidence coefficients for the degree of grey incidence at each time point. However, a serial incidence coefficient at different time points does not have the same influence on system behaviour. Therefore, the similarity of systematic development characterized by the degree of grey incidence is related to the weight of each point. Each factor has its own contribution in the evaluation. The weight value of a time point is the influence coefficient of the system. The larger the weight value is, the more important the coefficient is. Usually, the weight value depends on the decision maker's subjectivity, which may result in some errors. How to arrange 
the decision weights should be studied in the decisionmaking process. Determining the weight of incidence coefficient should cause the distribution density value of weighted grey incidence coefficients to balance; therefore, according to Proposition 1 and Theorem 1 in the appendix, we define the maximum constraint of weighted grey incidence entropy, and the weight vector is

$$
\omega_{0 i}=\Gamma_{0 i}{ }^{-1} b
$$

where

$$
\Gamma_{0 i}=\left(\begin{array}{cccccc}
\Delta_{0 i}(1) & -\Delta_{0 i}(2) & & & & \\
& \Delta_{0 i}(2) & -\Delta_{0 i}(3) & & & \\
\ldots & \ldots & \ldots & \ldots & \ldots & \ldots \\
& & & & \Delta_{0 i}(n-1) & -\Delta_{0 i}(n) \\
1 & 1 & 1 & \ldots & 1 & 1
\end{array}\right) \text {, }
$$$$
\omega_{0 i}=\left(\begin{array}{c}
\omega_{0 i}(1) \\
\omega_{0 i}(2) \\
\ldots \\
\omega_{0 i}(n)
\end{array}\right) \text {, }
$$$$
b=\left(\begin{array}{c}
0 \\
0 \\
\cdots \\
0 \\
1
\end{array}\right)
$$

3.7. Step VII: Calculation of the Degree of Grey Incidence. Assume that $X_{0}=\left(x_{0}(1), x_{0}(2), \cdots, x_{0}(n)\right)$ is a sequence of data representing a system's characteristics and $X_{i}$ are sequences of relevant factors, and let

$$
\gamma\left(X_{0}, X_{i}\right)=\sum_{k=1}^{n} \omega_{o i}(k) \gamma_{0 i}(k)
$$

where $\sum_{k=1}^{n} \omega_{0 i}(k)=1$ and $\Delta_{0 i}(k)$ are defined by (5). Then $\gamma\left(X_{0}, X_{i}\right)$ is called the weighted degree of grey incidence of $X_{i}$ with respect to $X_{0}$.

3.8. Step VIII: Determination of the Grades of Suppliers. Based on the degree of grey incidence, the priority of the $m$ suppliers is determinate, and the optimal supplier who has the maximal degree is selected.

\section{Practical Application of Green Supplier Selection Decision Maker for Process Industries}

In this section, we consider a practical application of green supplier selection decision maker for some chemical processing industry. The business of the chemical processing
TABLE 2: Alternatives versus criteria.

\begin{tabular}{lcccccccc}
\hline Supplier & C1 & C2 & C3 & C4 & C5 & C6 & C7 & C8 \\
\hline Supplier 1 & 2439 & $86 \%$ & 12 & 4 & 170 & 0.10 & 10 & 6.9 \\
Supplier 2 & 2567 & $90 \%$ & 12 & 3 & 260 & 0.08 & 13 & 7.0 \\
Supplier 3 & 2711 & $93 \%$ & 14 & 3 & 280 & 0.11 & 12 & 7.2 \\
Supplier 4 & 3099 & $94 \%$ & 10 & 2 & 260 & 0.10 & 11 & 6.7 \\
Supplier 5 & 2302 & $89 \%$ & 13 & 2.5 & 290 & 0.09 & 12 & 7.0 \\
Supplier 6 & 3115 & $92 \%$ & 12 & 3 & 250 & 0.09 & 11 & 6.9 \\
Supplier 7 & 2800 & $90 \%$ & 14 & 2 & 250 & 0.08 & 10 & 7.0 \\
\hline
\end{tabular}

industry is to change the chemical structure of natural materials in order to derive products of value to other industries or in daily life. Chemicals are produced from these raw materials, principally minerals, metals, and hydrocarbons in a series of processing steps. Further treatment, such as mixing and blending, is often required to convert them into endproducts (e.g., paints, adhesives, medicines, and cosmetics). It is known that the supplier selection of raw materials or natural materials is very important to the chemical processing industry. Surely, the cost is one of the most important factors for supplier selection. For quality, delivery, service, and technique capability, many suppliers can meet the requirements of the chemical processing industry. However, green production, pollution control, and environmental management may influence product environmental quality safety, even the development prospect of the enterprise. The data for this case study have been collected from the procurement department, which is accountable for the whole purchasing processes at a given chemical processing industry. An interview has been conducted for the purpose of data collection. Seven suppliers have responded with a quotation representing the prescribed product with their attributes. The proposed weighted grey incidence decision model is used to deal with small samples, and the data of supplier selection for the chemical processing industry is just a sample. Therefore, the methodology weighted grey incidence decision model can be used to select the green suppliers for process industries. Applying the proposed model to supplier selection decision implies that all the steps above have to be followed.

(1) Determination of selection index data: the structure of the decision problem considered in this study consists of seven alternatives, e.g., suppliers 1-7. For brevity, we only select the following indexes: product price (yuan), product qualification ratio (\%), delivery time (days), warranty (months), manufacturing capacity (kg per day), remanufacturing (\%), harmful materials released $(\mathrm{kg})$, and low carbon measures (g) as the decision criteria, and they are compiled as $C_{1}, C_{2}, C_{3}, C_{4}, C_{5}, C_{6}, C_{7}$, and $C_{8}$, respectively. Table 2 shows the alternatives versus the criteria matrix for all seven suppliers

(2) Generation of referential series $X_{0}$ : the referential series $X_{0}$ is the optimal value for each criterion, and $x_{0}(k)$ is some observation value; it may be the largest 
TABLe 3: Normalized data.

\begin{tabular}{llcccccccc}
\hline Supplier & $y_{i}(k)$ & C1 & C2 & C3 & C4 & C5 & C6 & C7 & C8 \\
\hline Supplier 1 & $y_{1}(k)$ & 0.9438 & 0.9149 & 0.8333 & 1.0000 & 0.5862 & 0.9091 & 1.0000 & 0.9710 \\
Supplier 2 & $y_{2}(k)$ & 0.8968 & 0.9574 & 0.8333 & 0.7500 & 0.8966 & 0.7273 & 0.7692 & 0.9571 \\
Supplier 3 & $y_{3}(k)$ & 0.8491 & 0.9894 & 0.7143 & 0.7500 & 0.9655 & 1.0000 & 0.8333 & 0.9306 \\
Supplier 4 & $y_{4}(k)$ & 0.7428 & 1.0000 & 1.0000 & 0.5000 & 0.8966 & 0.9091 & 0.9091 & 1.0000 \\
Supplier 5 & $y_{5}(k)$ & 1.0000 & 0.9468 & 0.7692 & 0.6250 & 1.0000 & 0.8182 & 0.8333 & 0.9571 \\
Supplier 6 & $y_{6}(k)$ & 0.7390 & 0.9787 & 0.8333 & 0.7500 & 0.8621 & 0.8182 & 0.9091 & 0.9710 \\
Supplier 7 & $y_{7}(k)$ & 0.8221 & 0.9574 & 0.7143 & 0.5000 & 0.8621 & 0.7273 & 1.0000 & 0.9571 \\
\hline
\end{tabular}

or the smallest of $\left\{x_{1}(k), x_{2}(k), \cdots, x_{7}(k)\right\}$. For indexes $C_{1}, C_{3}, C_{7}$, and $C_{8}$, the smallest is the best, and for indexes $C_{2}, C_{4}, C_{5}$, and $C_{6}$, the largest is the best. Therefore, $X_{0}=(2302,0.94,10,4,290$, $0.11,10,6.7)$ are used to compare the values of each corresponding supplier

(3) Normalization of data set: according to the above referential series $X_{0}$ and formulas (3a) and (3b)

$y_{i}(k)=\frac{x_{0}(k)}{x_{i}(k)}, \quad$ if $x_{0}(k)$ is the smallest one of

$$
x_{i}(k), i=1,2, \cdots, 7, k=1,2, \cdots, 8,
$$

$y_{i}(k)=\frac{x_{i}(k)}{x_{0}(k)}, \quad$ if $x_{0}(k)$ is the biggest one of

$$
x_{i}(k), i=1,2, \cdots, 7, k=1,2, \cdots, 8,
$$

the series data in this case can be normalized. The normalized data are tabulated in Table 3

(4) Construction of the differential information data: from the normalized data and formula (5)

$$
\begin{aligned}
\Delta_{0 i}(k)=\frac{1}{1+\lambda\left|1-y_{i}(k)\right|}, \\
\quad i=1,2, \cdots, 7, k=1,2, \cdots, 8,
\end{aligned}
$$

we take that $\lambda=1.5$ is some fixed number, we calculate the differential information data, and the differential information data are tabulated in Table 4

(5) Set up of grey incidence coefficient: according to the differential information data and formula (7)

$$
\gamma_{0 i}(k)=\frac{\min _{j} \min _{r} \Delta_{0 j}(r)+\xi \Delta_{0 i}(k)}{\min _{j} \min _{r} \Delta_{0 j}(r)+\xi \max _{j} \max _{r} \Delta_{0 i}(r)},
$$

the grey incidence coefficient is calculated and tabulated in Table 5
(6) Determination of the weight of grey incidence coefficient: according to the differential information data and formula (9) $\omega_{0 i}=\Gamma_{0 i}{ }^{-1} b$, where

$$
\begin{aligned}
\Gamma_{0 i} & =\left(\begin{array}{cccccc}
\Delta_{0 i}(1) & -\Delta_{0 i}(2) & & & & \\
& \Delta_{0 i}(0) & -\Delta_{0 i}(3) & & & \\
\ldots & \ldots & \ldots & \ldots & \ldots & \ldots \\
& & & & \Delta_{0 i}(6) & -\Delta_{0 i}(7) \\
1 & 1 & 1 & \ldots & 1 & 1
\end{array}\right), \\
\omega_{0 i} & =\left(\begin{array}{c}
\omega_{0 i}(1) \\
\omega_{0 i}(2) \\
\ldots \\
\omega_{0 i}(7)
\end{array}\right),
\end{aligned}
$$$$
b=\left(\begin{array}{c}
0 \\
0 \\
\cdots \\
0 \\
1
\end{array}\right) \text {, }
$$

we calculate the weights of grey incidence coefficients and tabulated in Table 6

(7) Calculation of the degree of grey incidence: according to the weights of grey incidence coefficients based on the grey relational coefficients and formula (11)

$$
\gamma\left(X_{0}, X_{i}\right)=\sum_{k=1}^{8}{\omega_{0 i}}_{i}(k) \gamma_{0 i}(k)
$$

the degree of the grey incidence is calculated and the values are tabulated in Table 7

(8) Grade of the suppliers: based on the degree of the grey incidence, the optimal supplier was selected. The priorities of the seven suppliers were supplier $1>$ supplier $3>$ supplier $4>$ supplier $\quad 5>$ supplier 
TABLE 4: Differential information data.

\begin{tabular}{lcccccccc}
\hline$\Delta_{0 i}(k)$ & C1 & C2 & C3 & C4 & C5 & C6 & C7 \\
\hline$\Delta_{01}(k)$ & 0.9223 & 0.8868 & 0.8000 & 1.0000 & 0.6170 & 0.8800 & 1.0000 & 0.9583 \\
$\Delta_{02}(k)$ & 0.8659 & 0.9400 & 0.8000 & 0.7273 & 0.8657 & 0.7097 & 0.7428 & 0.9396 \\
$\Delta_{03}(k)$ & 0.8155 & 0.9843 & 0.7000 & 0.7273 & 0.9508 & 1.000 & 0.8000 & 0.9057 \\
$\Delta_{04}(k)$ & 0.7216 & 1.0000 & 1.0000 & 0.5714 & 0.8657 & 0.8800 & 0.8800 & 1.0000 \\
$\Delta_{05}(k)$ & 1.0000 & 0.9261 & 0.7428 & 0.6400 & 1.0000 & 0.7857 & 0.8000 & 0.9396 \\
$\Delta_{06}(k)$ & 0.7186 & 0.9691 & 0.8000 & 0.7273 & 0.8286 & 0.7857 & 0.8800 & 0.9583 \\
$\Delta_{07}(k)$ & 0.7894 & 0.9400 & 0.7000 & 0.5714 & 0.8286 & 0.7097 & 1.0000 & 0.9396 \\
\hline
\end{tabular}

TABLE 5: Grey incidence coefficient.

\begin{tabular}{lcccccccc}
\hline$\gamma_{0 i}(k)$ & $\mathrm{C} 1$ & $\mathrm{C} 2$ & $\mathrm{C} 3$ & $\mathrm{C} 4$ & $\mathrm{C} 5$ & $\mathrm{C} 6$ & $\mathrm{C} 7$ & \multicolumn{1}{c}{ C8 } \\
\hline$\gamma_{01}(k)$ & 0.9505 & 0.9279 & 0.8727 & 1.0000 & 0.7562 & 0.9236 & 0.9735 \\
$\gamma_{02}(k)$ & 0.9147 & 0.9618 & 0.8727 & 0.8264 & 0.9145 & 0.8152 & 0.8364 \\
$\gamma_{03}(k)$ & 0.8826 & 0.9900 & 0.8091 & 0.8264 & 0.9687 & 1.0000 & 0.8727 & 0.9616 \\
$\gamma_{04}(k)$ & 0.8228 & 1.0000 & 1.0000 & 0.7273 & 0.9145 & 0.9236 & 0.9236 & 1.0000 \\
$\gamma_{05}(k)$ & 1.0000 & 0.9530 & 0.8364 & 0.7709 & 1.0000 & 0.8636 & 0.8727 \\
$\gamma_{06}(k)$ & 0.8210 & 0.9803 & 0.8727 & 0.8264 & 0.8909 & 0.8636 & 0.9236 \\
$\gamma_{07}(k)$ & 0.8660 & 0.9618 & 0.8091 & 0.7273 & 0.8909 & 0.8152 & 0.9735 \\
\hline
\end{tabular}

TABLE 6: The weights of grey incidence coefficients.

\begin{tabular}{cccccccc}
\hline$\omega_{0 i}(k)$ & C1 & C2 & C3 & C4 & C5 & C6 & C7 \\
\hline$\omega_{01}(k)$ & 0.1171 & 0.1217 & 0.1350 & 0.1080 & 0.1750 & 0.1227 & 0.1080 \\
$\omega_{02}(k)$ & 0.1176 & 0.1084 & 0.1273 & 0.1400 & 0.1177 & 0.1435 & 0.1371 \\
$\omega_{03}(k)$ & 0.1297 & 0.1075 & 0.1511 & 0.1455 & 0.1113 & 0.1058 & 0.1323 \\
$\omega_{04}(k)$ & 0.1449 & 0.1046 & 0.1046 & 0.1830 & 0.1208 & 0.1188 & 0.1188 \\
$\omega_{05}(k)$ & 0.1040 & 0.1123 & 0.1400 & 0.1625 & 0.1040 & 0.1323 & 0.1323 \\
$\omega_{06}(k)$ & 0.1433 & 0.1063 & 0.1288 & 0.1416 & 0.1243 & 0.1311 & 0.1171 \\
$\omega_{07}(k)$ & 0.1243 & 0.1044 & 0.1402 & 0.1717 & 0.1184 & 0.1383 & 0.0981 \\
\hline
\end{tabular}

$6>$ supplier $2>$ supplier 7 . Therefore, supplier 1 is the optimal supplier because it has the maximal degree of 0.9133 in Table 7

Through the actual calculation results of the proposed model for green supplier selection decision, we see that the results are most up to the mustard for green consideration. The optimal values of the green factors green production, pollution control, and environmental management are 0.11 , 10 , and 6.7, respectively, and the corresponding factors of an optimal supplier, "supplier 1," are 0.10, 10, and 6.9, respectively. Therefore, this proposed model can be applied to make the optimal green supplier select decision.

\section{Discussion}

Most of the methods for supplier selection processes rely on subjective index data of experts, such as TOPSIS technique,
TABLe 7: Degree of grey incidence.

\begin{tabular}{llc}
\hline Supplier & $\gamma\left(X_{0}, X_{i}\right)$ & Weighted degree of grey incidence \\
\hline Supplier 1 & $\gamma\left(X_{0}, X_{1}\right)$ & 0.9133 \\
Supplier 2 & $\gamma\left(X_{0}, X_{2}\right)$ & 0.8821 \\
Supplier 3 & $\gamma\left(X_{0}, X_{3}\right)$ & 0.9023 \\
Supplier 4 & $\gamma\left(X_{0}, X_{4}\right)$ & 0.8960 \\
Supplier 5 & $\gamma\left(X_{0}, X_{5}\right)$ & 0.8954 \\
Supplier 6 & $\gamma\left(X_{0}, X_{6}\right)$ & 0.8880 \\
Supplier 7 & $\gamma\left(X_{0}, X_{7}\right)$ & 0.8633 \\
\hline
\end{tabular}

analytic hierarchy process, and analytic network process. However, the weighted grey incidence decision model proposed in this manuscript depends on the objective data collected from the procurement department. These data used for supplier selection are more authentic and effective than scores by experts. Equally weighted factors and initial data sequences are used for calculating the degree of grey incidence in classical Deng's grey incidence analysis model. However, certain grey information cannot be directly obtained, and the correlation coefficients of each sequence at different times are of different importance to the system. Therefore, in this study, improved grey incidence coefficients using transformation sequences of the initial data and the maximum entropy method for determining the weights of improved grey incidence coefficients are proposed. Some grey information can be obtained more easily by using the grey transformation sequences, so the proposed model distinguished the new degree of grey incidence more effectively. The model was successfully used in the analysis of green 
supplier selection decision in the chemical processing industry. The examples demonstrate that the method is practical and reliable; it is also effective for decision-making in some other applied fields.

\section{Conclusion}

This paper presents an improved model for grey incidence to fix the weighted grey incidence coefficients for green supplier selection in process industries. New grey incidence coefficients are created by transformation sequences of the initial data. The weights are determinate in the objective entropy information method, which reflect the actual data. The method is based on the difference of index data to produce determinate weights. The proposed approach is suitable for decision-making under more uncertain environments. This paper proposes an evaluation method to determine the overall performance for each candidate supplier. The optimum decision can then be made based on the supplier's overall rating. The use of the proposed model can facilitate companylevel decision-making by using a systematic approach to select the appropriate supplier.

\section{Appendix}

In this section, some mathematical statements and their proofs are listed for convenience and content integrity. The following can be found in [32-35].

The distribution of the weighted grey incidence coefficients is defined below.

Definition 4. The distribution of the weighted grey incidence coefficients is defined so that

$$
p_{k}=\frac{\varrho_{0 i}(k) \Delta_{0 i}(k)}{\sum_{k=1}^{n} \Phi_{0 i}(k) \Delta_{0 i}(k)}
$$

is its density value.

According to $[32,33],\left\{p_{k}\right\}$ is a grey sequence.

Definition 5. The function

$$
H_{\otimes}\left(R_{i}\right)=-\sum_{k=1}^{n} p_{k} \ln p_{k}
$$

is called the weighted grey incidence entropy of $X_{i}$, where $\forall$ $k, p_{k} \geq 0, \sum_{k=1}^{n} p_{k}=1$.

The following proposition holds.

Proposition 1. [34, 35] If the density sequence of the distribution of the weighted grey incidence coefficient is $p=\left\{p_{k} \mid \forall k\right.$, $\left.p_{k} \geq 0, \sum_{k=1}^{n} p_{k}=1\right\}$ and $H \otimes\left(R_{i}\right)$ is the incidence entropy, then $H \otimes\left(R_{i}\right)$ is maximised when $p_{k}$ are equal.

Corresponding to a uniform distribution, the optimal weights of the incidence coefficients yield the maximum weighted grey incidence entropy by Proposition 1 .
Theorem 1. [34, 35] The solution to the problem

$$
\begin{array}{ll}
\max & H_{\otimes}\left(R_{i}\right)=-\sum_{k=1}^{n} p_{k} \ln p_{k} \\
\text { s.t. } & \sum_{k=1}^{n}{\omega_{0 i}}(k)=1, \quad \omega_{0 i}(k)>0, \\
& p_{k}=\frac{\omega_{0 i}(k) \Delta_{0 i}(k)}{\sum_{k=1}^{n} \varrho_{0 i}(k) \Delta_{0 i}(k)}
\end{array}
$$

is

$$
\begin{aligned}
p_{k} & =\frac{1}{n}, \\
\varpi_{0 i} & =\Gamma_{0 i}{ }^{-1} b,
\end{aligned}
$$

where

$\Gamma_{0 i}=\left(\begin{array}{cccccc}\Delta_{0 i}(1) & -\Delta_{0 i}(2) & & & & \\ & \Delta_{0 i}(2) & -\Delta_{0 i}(3) & & & \\ \ldots & \ldots & \ldots & \ldots & \ldots & \ldots \\ & & & & \Delta_{0 i}(n-1) & -\Delta_{0 i}(n) \\ 1 & 1 & 1 & \ldots & 1 & 1\end{array}\right)$,

${\omega_{0 i}}=\left(\begin{array}{c}\omega_{0 i}(1) \\ \varrho_{0 i}(2) \\ \ldots \\ \omega_{0 i}(n)\end{array}\right)$,

$b=\left(\begin{array}{c}0 \\ 0 \\ \cdots \\ 0 \\ 1\end{array}\right)$.

Proof. The Lagrange function of problem (19) is

$$
L\left(p_{k}, \lambda\right)=-\sum_{k=1}^{n} p_{k} \ln p_{k}+\lambda\left(\sum_{k=1}^{n} p_{k}-1\right)
$$

The necessary condition for the existence of extreme values implies that

$$
\left\{\begin{array}{l}
\frac{\partial L}{\partial p_{k}}=-\ln p_{k}+\lambda-1=0, \quad k=1,2, \cdots, n, \\
\frac{\partial L}{\partial \lambda}=\sum_{k=1}^{n} p_{k}-1=0 .
\end{array}\right.
$$


Hence, $p_{k}=e^{\lambda-1}(k=1,2, \cdots, n)$. This equal and $\sum_{k=1}^{n}$ $p_{k}=1$ lead to $p_{k}=1 / n$. From (17) and (19), we obtain

$$
\left\{\begin{array}{l}
\frac{\omega_{0 i}(k) \Delta_{0 i}(k)}{\sum_{k=1}^{n} \varrho_{0 i}(k) \Delta_{0 i}(k)}=\frac{1}{n}, \\
\sum_{k=1}^{n}{\omega_{0 i}}(k)=1 .
\end{array}\right.
$$

The above can be expressed as

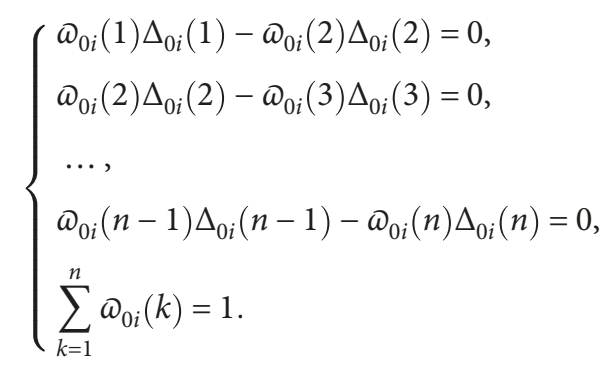

And the matrix form is $\Gamma_{0 i} \omega_{0 i}=b$, where

$$
\Gamma_{0 i}=\left(\begin{array}{cccccc}
\Delta_{0 i}(1) & -\Delta_{0 i}(2) & & & & \\
& \Delta_{0 i}(2) & -\Delta_{0 i}(3) & & & \\
\ldots & \ldots & \ldots & \ldots & \ldots & \ldots \\
& & & & \Delta_{0 i}(n-1) & -\Delta_{0 i}(n) \\
1 & 1 & 1 & \ldots & 1 & 1
\end{array}\right) \text {, }
$$$$
{\omega_{0 i}}=\left(\begin{array}{c}
\omega_{0 i}(1) \\
\omega_{0 i}(2) \\
\ldots \\
\omega_{0 i}(n)
\end{array}\right) \text {, }
$$$$
b=\left(\begin{array}{c}
0 \\
0 \\
\cdots \\
0 \\
1
\end{array}\right) \text {. }
$$

The determinant of $\Gamma_{0 i}$ is

$$
\left|\Gamma_{0 i}\right|=\left|\begin{array}{cccccc}
\Delta_{0 i}(1) & -\Delta_{0 i}(2) & & & & \\
& \Delta_{0 i}(2) & -\Delta_{0 i}(3) & & & \\
\ldots & \ldots & \ldots & \ldots & \ldots & \ldots \\
& & & & \Delta_{0 i}(n-1) & -\Delta_{0 i}(n) \\
1 & 1 & 1 & 1 & 1 & 1
\end{array}\right| .
$$

We add the $(n-1)$ th row to the $(n-2)$ th row, add the $(n-2)$ th row to the $(n-3)$ th row, until we add the third row to the second row, and add the second row to the first row; then we have

$$
\left|\Gamma_{0 i}\right|=\left|\begin{array}{ccccccc}
\Delta_{0 i}(1) & & & & & -\Delta_{0 i}(n) \\
& \Delta_{0 i}(2) & & & & -\Delta_{0 i}(n) \\
\ldots & \ldots & \ldots & \ldots & \ldots & -\Delta_{0 i}(n) \\
& & & & -\Delta_{0 i}(n-1) & -\Delta_{0 i}(n) \\
1 & 1 & 1 & 1 & 1 & 1
\end{array}\right| .
$$

Now, for $k=1,2, \ldots, n-1$, we add the $k$ th column multiplied by $\left(\Delta_{0 i}(k)\right) /\left(\Delta_{0 i}(k)\right)$ to the $n$th column, and we obtain

$$
\left|\Gamma_{0 i}\right|=\left|\begin{array}{cccccc}
\Delta_{0 i}(1) & & & & & \\
& \Delta_{0 i}(2) & & & & \\
\ldots & \ldots & \ldots & \ldots & \ldots & \\
& & & & \Delta_{0 i}(n-1) & \\
1 & 1 & 1 & 1 & 1 & 1+\sum_{k=1}^{n-1} \frac{\Delta_{0 i}(n)}{\Delta_{0 i}(k)}
\end{array}\right| \text {, }
$$

which is

$$
\left\|\Gamma_{0 i}\right\|=\prod_{k=1}^{n-1} \Delta_{0 i}(k)\left(1+\prod_{k=1}^{n-1} \frac{\Delta_{0 i}(n)}{\Delta_{0 i}(k)}\right) .
$$

From (3a) and (3b), we know that $\left\|\Gamma_{0 i}\right\| \neq 0$. Therefore, the system of the linear equations has a unique solution. Hence, the weight vector is ${\omega_{0 i}}=\Gamma_{0 i}{ }^{-1} b$.

\section{Data Availability}

The data used to support the findings of this study are available from the corresponding author upon request.

\section{Conflicts of Interest}

The authors declare that there are no conflicts of interest regarding the publication of this paper.

\section{Acknowledgments}

The authors' work was supported by the Chongqing Municipal Social Science Planning Commission Project of China (2016WT37), Science and Technology Research Project of Chongqing Education Commission (KJ1601902), and the open research fund of Chongqing Key Laboratory of Electronic Commerce Supply Chain System (1456026). 


\section{References}

[1] A. Aguezzoul, "Overview on supplier selection of goods versus 3PL selection," Journal of Logistics Management, vol. 1, no. 3, pp. 18-23, 2012.

[2] D. Beil, "Supplier selection," in Encyclopedia of Operations Research and Management Science, Wiley, New York, NY, USA, 2010.

[3] R. Singh, H. Rajput, V. Chaturvedi, and J. Vimal, "Supplier selection by technique of order preference by similarity to ideal solution (TOPSIS) method for automotive industry," International Journal of Advanced Technology \& Engineering Research, vol. 2, no. 2, pp. 157-160, 2012.

[4] F. T. S. Chan, N. Kumar, M. K. Tiwari, H. C. W. Lau, and K. L. Choy, "Global supplier selection: a fuzzy-AHP approach," International Journal of Production Research, vol. 46, no. 14, pp. 3825-3857, 2008.

[5] S. Hossein Cheraghi, M. Dadashzadeh, and M. Subramanian, "Critical success factors for supplier selection: an update," Journal of Applied Business Research, vol. 20, no. 2, pp. 91108, 2011.

[6] W. Ho, X. Xu, and P. K. Dey, "Multi-criteria decision making approaches for supplier evaluation and selection: a literature review," European Journal of Operational Research, vol. 202, no. 1, pp. 16-24, 2010.

[7] A. Kumar, V. Jain, and S. Kumar, "A comprehensive environment friendly approach for supplier selection," Omega, vol. 42, no. 1, pp. 109-123, 2014.

[8] O. Gurel, A. Z. Acar, I. Onden, and I. Gumus, "Determinants of the green supplier selection," Procedia-Social and Behavioral Sciences, vol. 181, pp. 131-139, 2015.

[9] G. Noci, "Designing green vendor rating systems for the assessment of a suppliers environmental performance," European Journal of Purchasing \& Supply Management, vol. 3, no. 2, pp. 103-114, 1997.

[10] R. Handfield, S. V. Walton, R. Sroufe, and S. A. Melnyk, "Applying environmental criteria to supplier assessment: a study in the application of the analytical hierarchy process," European Journal of Operational Research, vol. 141, no. 1, pp. 70-87, 2002.

[11] P. Humphreys, R. McIvor, and F. Chan, "Using case-based reasoning to evaluate supplier environmental management performance," Expert Systems with Applications, vol. 25, no. 2, pp. 141-153, 2003.

[12] P. K. Humphreys, Y. K. Wong, and F. T. S. Chan, "Integrating environmental criteria into the supplier selection process," Journal of Materials Processing Technology, vol. 138, no. 1-3, pp. 349-356, 2003.

[13] A. H. I. Lee, H. Y. Kang, C. F. Hsu, and H. C. Hung, "A green supplier selection model for high-tech industry," Expert Systems with Applications, vol. 36, no. 4, pp. 79177927, 2009.

[14] R. J. Kuo, Y. C. Wang, and F. C. Tien, "Integration of artificial neural network and MADA methods for green supplier selection," Journal of Cleaner Production, vol. 18, no. 12, pp. 11611170, 2010.

[15] L. de Boer, E. Labro, and P. Morlacchi, "A review of methods supporting supplier selection," European Journal of Purchasing \& Supply Management, vol. 7, no. 2, pp. 75-89, 2001.
[16] K. Govindan, S. Rajendran, J. Sarkis, and P. Murugesan, "Multi criteria decision making approaches for green supplier evaluation and selection: a literature review," Journal of Cleaner Production, vol. 98, pp. 66-83, 2015.

[17] D. Ju-Long, "Control problems of grey systems," Systems \& Control Letters, vol. 1, no. 5, pp. 288-294, 1982.

[18] J. L. Deng, "Grey information space," Journal of Grey System, vol. 1, no. 2, pp. 103-117, 1989.

[19] J. L. Deng, "Introduction to grey system theory," The Journal of Grey System, vol. 1, pp. 1-24, 1989.

[20] B. Zeng, Y. Tan, H. Xu, J. Quan, L. Wang, and X. Zhou, "Forecasting the electricity consumption of commercial sector in Hong Kong using a novel grey dynamic prediction model," Journal of Grey System, vol. 30, no. 1, pp. 157-172, 2018.

[21] B. Zeng, H. Duan, Y. Bai, and W. Meng, "Forecasting the output of shale gas in China using an unbiased grey model and weakening buffer operator," Energy, vol. 151, pp. 238-249, 2018.

[22] B. Zeng and S. F. Liu, "A self-adaptive intelligence gray prediction model with the optimal fractional order accumulating operator and its application," Mathematical Methods in the Applied Sciences, vol. 23, no. 1, pp. 1-15, 2017.

[23] P. Golinska, M. Kosacka, R. Mierzwiak, and K. WernerLewandowska, "Grey decision making as a tool for the classification of the sustainability level of remanufacturing companies," Journal of Cleaner Production, vol. 105, no. 15, pp. 28-40, 2015.

[24] S. F. Liu, Y. J. Yang, and L. F. Wu, Grey System Theory and Its Application, Beijing: Science Press, 2014.

[25] C. H. Tsai, C. L. Chang, and L. Chen, "Applying grey relational analysis to the vendor evaluation model," International Journal of The Computer, The Internet and Management, vol. 11, no. 3, pp. 45-53, 2003.

[26] C. C. Yang and B. S. Chen, "Supplier selection using combined analytical hierarchy process and Grey relational analysis," Journal of Manufacturing Technology Management, vol. 17, no. 7, pp. 926-941, 2006.

[27] G.-D. Li, D. Yamaguchi, and M. Nagai, "A grey-based rough decision-making approach to supplier selection," International Journal of Advanced Manufacturing Technology, vol. 36, no. 9-10, pp. 1032-1040, 2008.

[28] W.-Y. Wu, C.-J. Bai, and O. K. Gupta, “A hypermarket site selection model using the grey multi-objective decision method," International Journal of Logistics Systems and Management, vol. 2, no. 1, pp. 68-77, 2006.

[29] H. J. Cao, F. Liu, C. B. Li, and C. Liu, "An integrated method for product material selection considering environmental factors and a case study," Materials Science Forum, vol. 532-533, pp. 1032-1035, 2006.

[30] J. Sarkis, Greening the Supply Chain, Springer, London, 2006.

[31] C. C. Yang, K. J. Yang, and S. Y. Peng, "Exploration strategies and key activities for the system of environmental management," Total Quality Management \& Business Excellence, vol. 22, no. 11, pp. 1179-1194, 2011.

[32] Q. S. Zhang, X. J. Guo, and J. L. Deng, "Grey relation entropy method of grey relation analysis," Systems Engineering-Theory \& Practice, vol. 8, no. 8, pp. 7-11, 1996.

[33] Q. S. Zhang, Grey Difference Theory of Hazy Set, The Press of Petroleum Industry, Beijing, 2002. 
[34] L. L. Pei, W. M. Chen, J. F. Cui, and G. B. Zhuang, "Weighted degree of grey incidence based on optimization entropy," in 2009 IEEE International Conference on Grey Systems and Intelligent Services (GSIS 2009), pp. 10-12, Nanjing, China, 2009.

[35] J. Quan, B. Zeng, and L. Y. Wang, "Maximum entropy methods for weighted grey incidence analysis and applications," Grey Systems: Theory and Application, vol. 8, no. 2, pp. 144-155, 2018. 


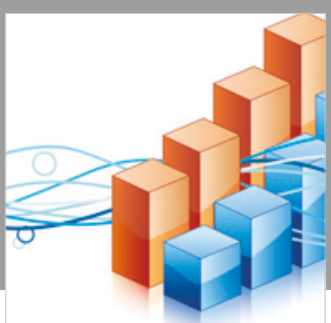

Advances in

Operations Research

\section{-n-m}
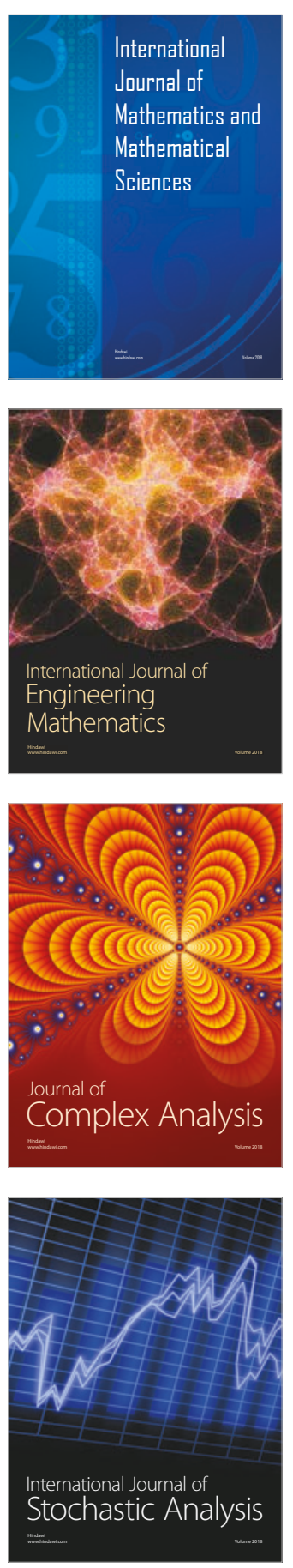
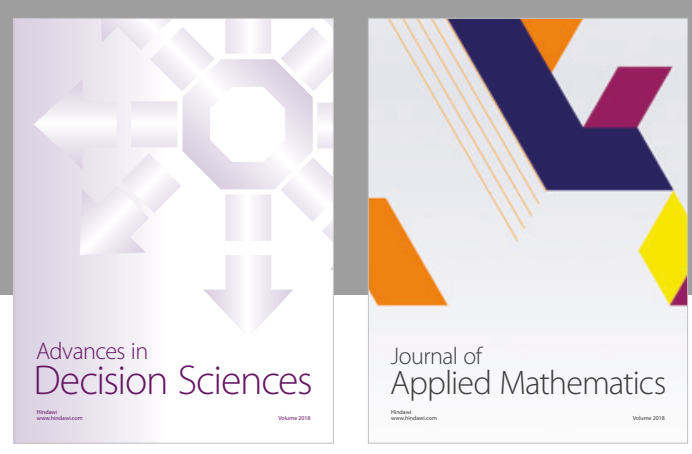

Journal of

Applied Mathematics
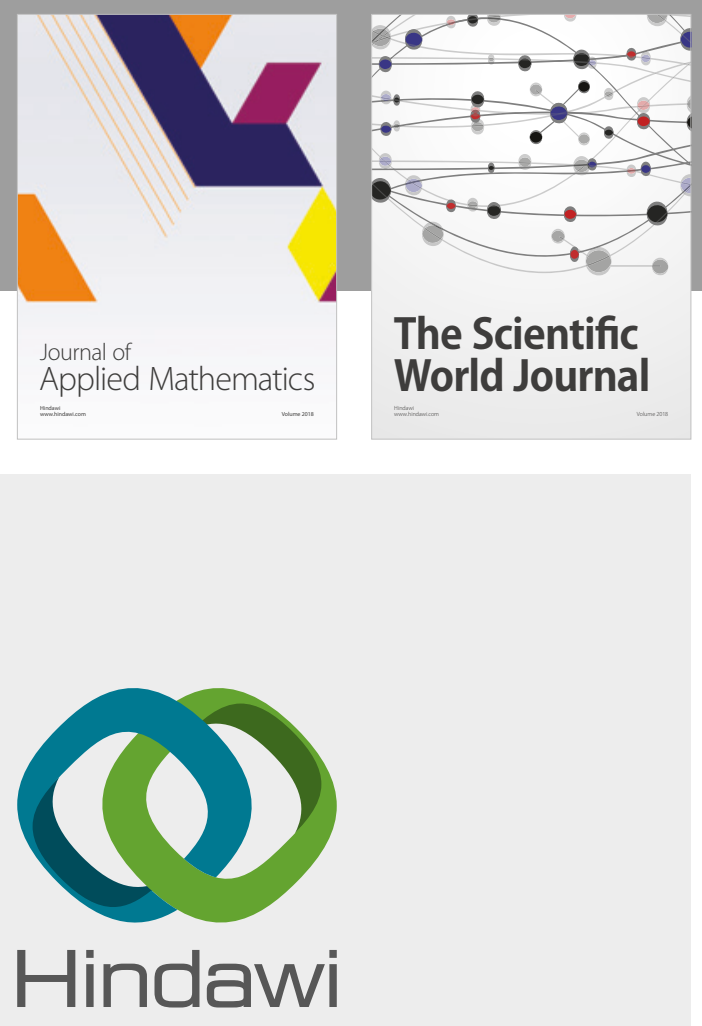

Submit your manuscripts at

www.hindawi.com

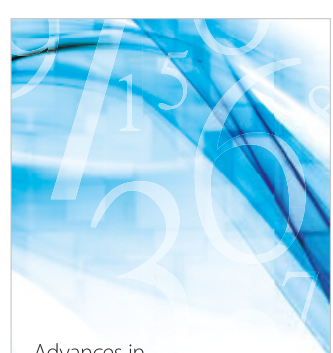

Advances in
Numerical Analysis
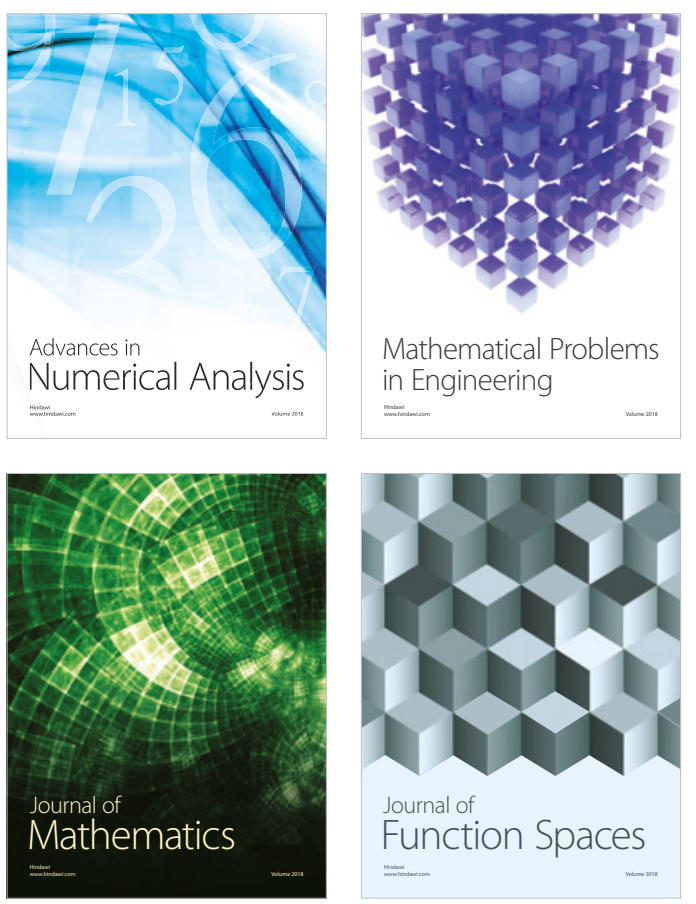

Mathematical Problems in Engineering

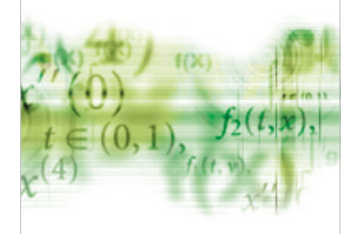

International Journal of

Differential Equations

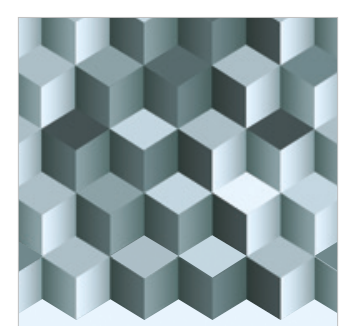

Journal of

Function Spaces
The Scientific

World Journal

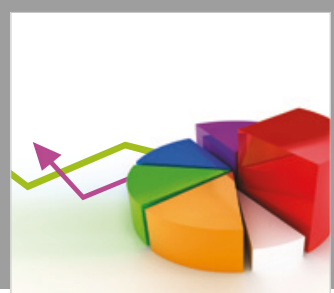

Journal of

Probability and Statistics
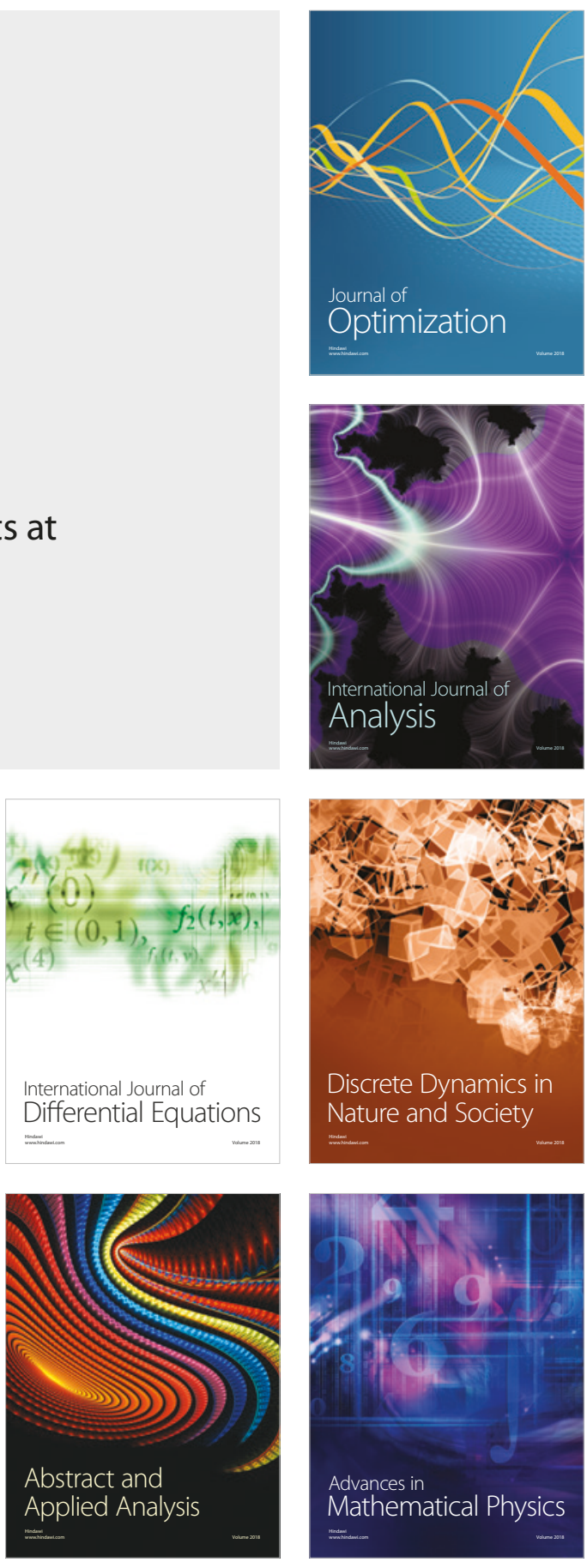